\title{
PENGARUH SISTEM INFORMASI AKUNTANSI PERSEDIAAN BARANG TERHADAP PENGENDALIAN INTERN PERSEDIAAN BARANG PADA TOKO BESI DAN BANGUNAN SERBAGUNA DI AJIBARANG
}

\author{
Oleh, \\ Mugiarti (mugiarti27@yahoo.co.id) \\ Rofi Rachmantiko (rofirachmatiko@gmail.com) \\ Siska Khurniyati Supraja (titasupraja@gmail.com) \\ Program Magister Sains S2 \\ Universitas Jenderal Soedirman \\ Purwokerto
}

\begin{abstract}
This study aimed to examine the effect of variable $X$, namely Accounting Information System Inventory and $Y$ is the Internal Control Inventory of Toko Besi dan Bangunan Serba Guna at Ajibarang. Based on the research results show that the Accounting Information System Inventory $(X)$ is categorized either by value 3.79. Internal Control Inventory $(Y)$ is also said to be good with a value of 4.11.

Effect of Accounting Information System for Internal Control Inventory based research methods, namely, 1) Correlation, based on calculations between variables $X$ and $Y$ has a strong relationship that is equal to 0.750,2) Regression, based on the data through a simple regression of $Y=0.327+0.895 X$ which means each an increase of Accounting Information Systems Inventory role in Internal Control Inventory amounted to $56.30 \%$, while the remaining $43.70 \%$ due to the influence of others.

At the end, the authors expressed conclusions and suggestions to the company as an input. Although the Accounting Information Systems Inventory is already done well, the system implemented should always follow the conditions that occur at any time and be a directed preparation. Also, Internal Control Inventory is already good and sufficient, therefore, it needs to be maintained and enhanced in order to generate a better and more efficient Internal Control Inventory.
\end{abstract}

Keywords : Accounting Information Systems Inventory; and Internal Control Inventory.

\begin{abstract}
ABSTRAK
Penelitian ini bertujuan untuk meneliti pengaruh variabel $\mathrm{X}$ yaitu Sistem Informasi Akuntansi Persediaan Barang dan variabel $\mathrm{Y}$ yaitu Pengendalian Intern persediaan barang di Toko Besi dan Bangunan Serba Guna di Ajibarang. Berdasarkan
\end{abstract}




\section{Performance - Vol.22 No.2 September 2016}

hasil perhitungan didapat bahwa Sistem Informasi Akuntansi persediaan barang (X) dikategorikan baik dengan nilai 3,79. Pengendalian Intern Persediaan Barang (Y) juga dikatakan baik dengan nilai 4,11.

Pengaruh Sistem Informasi Akuntansi Persediaan Barang terhadap Pengendalian Intern Persediaan Barang yang berdasarkan metode penelitian yaitu, 1) Korelasi, berdasarkan hasil perhitungan antara variabel $\mathrm{X}$ dan variabel $\mathrm{Y}$ memiliki hubungan yang kuat yaitu sebesar 0,750. 2) Regresi, berdasarkan olah data melalui regresi sederhana diketahui $\mathrm{Y}=0,327+0,895 \mathrm{X}$ yang berarti setiap terjadi kenaikan Sistem Informasi Akuntansi persediaan barang sebesar 0,327 menyebabkan terjadi kenaikan pengendalian intern sebesar 0,895. 3) Koefisien Determinasi, berdasarkan pada Koefisien Sistem Informasi Akuntansi Persediaan Barang berperan dalam Pengendalian Intern Persediaan Barang sebesar 56,30\% sedangkan sisanya 43,70 disebabkan oleh pengaruh yang lain.

Diakhir penulis menyampaikan kesimpulan dan saran-saran kepada pihak perusahaan sebagai bahan masukan. Meskipun Sistem Informasi Akuntasi persediaan barang yang dilakukan sudah berjalan dengan baik, hendaknya sistem yang akan dilaksanakan selalu mengikuti kondisi yang terjadi pada suatu saat dan disusun secara terarah. Pengendalian Intern persediaan barang yang dilakukan sudah baik dan memadai oleh karena itu harus tetap dipertahankan dan ditingkatkan agar menghasilkan Pengendalian Intern persediaan barang yang lebih baik dan efisien.

Kata kunci: Sistem informasi akuntansi persediaan barang; Pengendalian intern persediaan barang.

\section{PENDAHULUAN}

\section{Latar Belakang Penelitian}

Pada umumnya badan usaha dalam kegiatan usahanya menerapkan Sistem Informasi Akuntansi Persediaan Barang guna mencapai efektifitas pengendalian persediaan barang dengan dihasilkannya informasi persediaan barang yang berkualitas. Perusahaan distributor adalah salah satu bentuk kegiatan usaha yang menerapkan Sistem Informasi Akuntansi Persediaan Barang dalam menjalan aktivitas operasional usahanya. Menurut Peraturan Mentri Perdagangan Indonesia
Nomor 11 Tahun 2016 pengertian distributor adalah : "perusahaan perdagangan nasional yang bertindak untuk dan atas namanya sendiri berdasarkan perjanjain yang melakukan pembelian, penyimpanan, penjualan, serta pemasaran barang/jasa yang dimiliki/ dikuasai."

Karena menyediakan berbagai macam barang dengan jenis, bentuk, merk, ukuran, harga, dan sifatnya yang berbeda-beda, barang dagang pada perusahaan ini rentan terhadap berbagai 
kerusakan, keusangan, kekurangan persediaan, dan kehilangan.

Kehilangan dan kerusakan akan barang dagang dapat merugikan perusahaan karena secara langsung dapat mengurangi jumlah persediaan barang dagang perusahaan. Selain itu, hal tersebut dapat menyebabkan hilangnya kepercayaan konsumen dan pihak lainnya yang berkepentingan terhadap perusahaan.

Berdasarkan paparan permasalahan di atas, maka perusahaan perlu mempunyai suatu pengendalian internal persediaan barangnya. Pengendalian internal suatu perusahaan merupakan segala upaya yang dilakukan perusahaan untuk mengarahkan seluruh kegiatan agar tujuan perusahaan dapat dicapai secara efektif, efisien, dan ekonomis, segala sumber daya dapat dimanfaatkan dan ditaatinya segala ketentuan yang berlaku.

Dengan adanya pengendalian yang baik dan teratur dalam mengelola persediaan barang dagang, pimpinan perusahaan akan memperoleh laporanlaporan yang bermanfaat untuk meningkatkan efektifitas perusahaan, juga membantu dalam mengambil kebijakan keputusan maupun pertanggungjawaban dalam memimpin perusahaan.

Pengendalian internal atas persediaan barang diharapkan dapat menciptakan aktivitas pengendalian terhadap perusahaan yang efektif dalam menentukan jumlah persediaan optimal yang dimiliki perusahaan, mencegah berbagai tindakan pelanggaran dan penyelewengan yang dapat merugikan perusahaan, pelanggaran atas kebijakan yang ditetapkan atas persediaan, serta memberikan pengamatan fisik terhadap persediaan barang dari pencurian dan kerusakan.

Penelitian sebelumnya yang dilakukan pada tahun 2014 oleh Desti Kurnia Sari dan Rizal Effendi tentang "Pengaruh Sistem Informasi Akuntansi dalam Pengendalian Barang Dagang pada CV. Graha Gallery Palembang" yang diperoleh kesimpulan bahwa dari hasil penelitian pengendalian yang dilakukan pada CV. Graha Gallery Palembang masih memiliki beberapa kelemahan antara lain, terjadi penumpukkan barang pada bagian gudang, tidak adanya pemisahan tugas antara bagian penerimaan dengan bagian penyimpanan, adanya ketidakcocokkan pencatatan pada kartu stok dengan jumlah barang yang ada pada komputer.

\section{Identifikasi Masalah}

Berdasarkan latar belakang masalah yang diuraikan di atas sebelumnya, maka penulis merumuskan permasalahan sebagai berikut:

1. Bagaimana Sistem Informasi Akuntansi persediaan barang pada Toko Besi dan Bangunan Serba Guna di Ajibarang?;

2. Bagaimana Pengendalian Internal persediaan barang pada Toko Besi dan Bangunan Serba Guna di Ajibarang?; dan

3. Berapa besar pengaruh Sistem Informasi Akuntansi persediaan barang terhadap Pengendalian Internal 


\section{Performance - Vol.22 No.2 September 2016}

persediaan barang pada Toko Besi dan Bangunan Serba Guna di Ajibarang?

\section{Tujuan Penelitian}

Berdasarkan identifikasi masalah di atas, maka penelitian yang dilakukan oleh penulis memiliki tujuan sebagai berikut:

1. Untuk mengetahui pelaksanaan Sistem Informasi Akuntansi persediaan barang pada Toko Besi dan Bangunan Serba Guna di Ajibarang;

2. Untuk mengetahui Pengendalian Internal persediaan barang pada Toko Besi dan Bangunan Serba Guna di Ajibarang; dan

3. Untuk mengetahui bersarnya pengaruh Sistem Informasi Akuntansi persediaan barang terhadap Pengendalian Internal persediaan barang pada Toko Besi dan Bangunan Serba Guna di Ajibarang.

\section{TINJAUAN PUSTAKA}

\section{Sistem Informasi Akuntansi}

Menurut Susanto Azhar (2007:18)

informasi yang berkualitas adalah informasi yang didalamnya bukan saja diperlukan adanya keakurasian dan kecepatan akan tetapi juga diperlukan adanya kesesuaian dengan kebutuhan manajemen dan kelengkapan dari informasi yang dihasilkan.

Informasi merupakan hasil atau keluaran dari sistem informasi. Definisi sistem informasi menurut Susanto Azhar (2007:61) merupakan komponenkomponen yang saling berhubungan dan bekerja sama untuk mengumpulkan, memproses, menyimpan, dan mendistribusikan informasi tersebut untuk mendukung proses pengambilan keputusan, koordinasi dan pengendalian.

\section{Pengertian Sistem Informasi Akuntansi}

Sistem informasi akuntansi menurut Krismaji (2004:4) adalah sebuah sistem yang memproses data transaksi guna menghasilkan informasi yang bermanfaat untuk merencanakan, mengendalikan dan mengoperasikan bisnis. Sedangkan sistem informasi akuntansi menurut La Midjan dan Susanto Azhar (2001:45) yaitu : "Suatu sistem pengolah dokumen akuntansi yang merupakan koordinasi manajemen, alat, dan metode berinteraksi secara harmonis dalam wadah organisasi yang berstruktur untuk menghasilkan informasi keuangan dan informasi akuntansi manajemen yang terstruktur pula."

\section{Sistem Informasi Akuntansi Persediaan Barang}

Persediaan merupakan harta yang sensitif terhadap penurunan harga pasar, pencurian, kerusakan, dan kelebihan biaya akibat salah arus. Oleh sebab itu perlu adanya suatu sistem informasi akuntansi persediaan yang baik agar pengelolaan persediaan dapat terlaksanakan secara efektif.

Sistem informasi akuntansi persediaan ini tidak berdiri sendiri, tetapi saling berkaitan dengan sistem-sistem lainnya, di antaranya adalah sistem pembelian, sistem retur pembelian, sistem penjualan, dan sistem retur penjualan. 
La Midjan dan Susanto Azhar (2001:150) mengemukakan bahwa pentingnya suatu sistem akuntansi persediaan dengan alasan sebagai berikut:

1. Sebagian besar kekayaan perusahaan terutama perusahaan dagang dan industri pada umumnya tertanam pada persediaan. Oleh karenanya perlu disusun sistem dan prosedurnya agar persediaan selain dapat ditingkatkan efisiensinya juga dapat ditingkatkan efektivitasnya;

2. Persediaan bagi perusahaan dagang dan industri harus diamankan dari kemungkinan pencurian, kebakaran, kerusakan, dan lain-lain demi mempertahankan kontinuitas perusahaan; dan

3. Persediaan harus ditangani dengan baik selain penyimpanan dan pengeluarannya juga pemasukkan ke perusahaan. Kesalahan dalam pemasukkan harga dan kualitas akan mempengaruhi baik terhadap hasil produksi maupun terhadap harga penjualannya.

\section{Pengendalian Internal Persediaan Barang}

La Midjan dan Susanto Azhar (2001:155) memberikan pendapat mengenai pengendalian internal persediaan sebagai berikut: "Semua metode, tindakan dan pencatatannya dilaksanakan untuk mengamankan persediaan sejak proses mendatangkannya, menerimanya, menyimpannya, dan mengeluarkannya baik secara fisik maupun secara kualitas.
Termasuk di dalamnya penentuan dan pengaturan jumlah persediaan."

Teknik-teknik dalam pengendalian persediaan menurut La Midjan dan Susanto Azhar (2001:156) adalah sebagai berikut:

1. Persediaan minimum, merupakan jumlah persediaan pada titik di mana pesanan atas persediaan tersebut harus dilaksanakan (reorder point);

2. Reorder point, merupakan rata-rata pemakaian barang selama lead time dan safety stock;

3. Lead time adalah jangka waktu antara saat pemesanan dilaksanakan sampai barang tersebut diterima;

4. Safety stock merupakan jumlah persediaan yang selalu harus tersedia sebagai "persediaan besi" untuk menjaga situasi kemungkinan terjadinya kesulitan mendapatkan perse-diaan tersebut suatu saat;

5. Persediaan maksimum, merupakan persediaan secara maksimum atau optimum boleh tersedia dalam perusahaan dan diperhitungkannya berdasarkan perkiraan; dan

6. Jumlah pemesanan ekonomis (Economic Order Quantity) merupakan jumlah besarnya pesanan yang secara ekonomis menguntungkan yaitu besarnya pesanan yang menimbulkan biaya pemesanan (ordering Cost) dan biaya penyimpanan (carrying Cost) yang minimal."

Kebijakan penanganan / pengendalian internal persediaan 


\section{Performance - Vol.22 No.2 September 2016}

merupakan kebijakan-kebijakan yang akan mengatur akumulasi persediaan. Beberapa hal yang tercakup menurut Mulyadi (2001:569) adalah sebagai berikut:

1. Permintaan pembelian dibuat berdasarkan kartu persediaan yang menunjukkan persediaan yang mendekati persediaan minimum;

2. Sejumlah barang yang akan dibeli dalam jumlah besar harus mendapatkan persetujuan pimpinan;

3. Kuantitas persediaan yang dipesan harus disetujui oleh kepala gudang;

4. Kartu-kartu persediaan yang menunjukkan persediaan yang sudah mendekati persediaan yang minimum, harus dikeluarkan dari tempat penyimpanan; dan

5. Tidak boleh ada bahan-bahan (persediaan) yang keluar dari gudang tanpa ada bon permintaan barang.

Hubungan Penerapan Sistem Informasi Akuntansi Persediaan Barang dengan Pengendalian Internal Persediaan Barang

Persediaan tentunya merupakan asset/ aktiva yang penting dan berharga bagi kegiatan perusahaan untuk dapat menjalankan usahanya, sebab sebagian besar kekayaan perusahaan pada umumnya tertanam dalam persediaan, yang jika tidak ditingkatkan efisiensi dan efektifitasnya, maka terpengaruh pada harga dan kualitasnya yang pada akhirnya berpengaruh pada laporan keuangan perusahaan. Risiko yang timbul dari persediaan, beberapa diantaranya yaitu dari kebijakan perusahaan untuk mengatur assetnya dan prosedur - prosedur baik pemasukan barang maupun pengeluaran barang, adanya keterlambatan waktu pelaporan, ketidakakuratan jumlah persediaan, laporan pendukung tidak lengkap, tidak tersediannya informasi pada saat dibutuhkan, hal ini akan menghasilkan kualitas informasi persediaan yang kurang berkualitas, agar tidak terjadi kurang berkualitasnya informasi persediaan perlu dihindari adanya hal- hal yang dapat menimbulkan resiko yang akan timbul.

Tujuan utama dari pengendalian intern adalah untuk menjaga asset dan pencatatan persediaan yang memadai dalam laporan keuangan oleh karena itu diperlukan pengendalian internal atas persediaan barang. Pengendalian internal persediaan barang bisa dikatakan efektif jika didalamnyaa terdapat pemenuhan unsur - unsur pengendalian intern dan pemenuhan dari tujuan pengendalian intern itu sendiri yaitu:

1. Keandalan Laporan Persediaan ;

2. Ketaatan terhadap kebijakan dan prosedur yang berlaku terkait persediaan barang; dan

3. Efektifitas dan Efisiensi operasi persediaan barang (COSO dalam Fauzan, 2003 : 59)

\section{Kerangka Pemikiran}

Dari berbagai teori yang menjelaskan mengenai Sistem Informasi Akuntansi persediaan barang dan 
Pengendalian Internal persediaan barang dapat disimpulkan dalam sebuah kerangka pemikira sebagai gambaran sederhana atas permasalahan yang akan diteliti dalam penelitian ini. Kerangka pemikiran yang ada dalam penelitian ini digambarkan sebagai berikut:

Gambar 1. Pengaruh Sistem Informasi Akuntansi Persediaan terhadap Pengendalian Internal Persediaan Barang.

\begin{tabular}{|c|c|}
\hline $\begin{array}{c}\text { Sistem } \\
\text { Infromasi } \\
\text { Akuntansi } \\
\text { Persediaan } \\
\text { (X) }\end{array}$ & $\begin{array}{l}\text { Pengendalian } \\
\text { Internal } \\
\text { Persediaan } \\
\text { (Y) }\end{array}$ \\
\hline $\begin{array}{l}\text { 1. Perangkat } \\
\text { Keras } \\
\text { (hardware) } \\
\text { 2. Perangkat } \\
\text { Lunak } \\
\text { (software) } \\
\text { 3. Sumber } \\
\text { Daya } \\
\text { Manusia } \\
\text { (brainware) } \\
\text { 4. Prosedur } \\
\text { 5. Database } \\
\text { 6. Jaringan } \\
\text { Komunikasi } \\
\text { (nerwork) }\end{array}$ & $\begin{array}{l}\text { 1. Lingkungan } \\
\text { Pengendalian } \\
\text { 2. Penetapan } \\
\text { Risiko } \\
\text { 3. Aktivitas } \\
\text { Pengendalian } \\
\text { 4. Informasi } \\
\text { dan } \\
\text { Komunikasi } \\
\text { 5. Pemantauan }\end{array}$ \\
\hline
\end{tabular}

\section{METODE PENELITIAN Desain Penelitian}

Metode penelitian yang dipakai dalam penelitian ini adalah metode penelitian deskriptif (descriptive research) dan metode penelitian verifikatif (verificative research). Penelitian deskriptif adalah penelitian terhadap masalah-masalah berupa fakta-fakta dari suatu populasi dan bertujuan untuk memperoleh deskripsi tentang Sistem Informasi Akuntansi persediaan barang dan Pengendalian Internal persediaan barang. Di mana dalam penelitian ini akan menguji pengaruh Sistem Informasi Akuntansi persediaan barang (X) pada Pengendalian Internal persediaan barang (Y) di Toko Besi dan Bangunan Serba Guna di Ajibarang, sehingga dengan metode deskriptif penulis mengharapkan akan mendapatkan data, hasilnya kemudian diolah, dan dianalisis serta disimpulkan. Kesimpulan tersebut berlaku untuk seluruh populasi, sehingga tujuan penelitian dapat dicapai secara efektif.

\section{Populasi dan Sampel}

Populasi dalam penelitian ini adalah karyawan atau pegawai dari bagian-bagian di Toko Besi dan Bangunan Serba Guna di Ajibarang sebanyak 23 orang yang terkait dengan judul, sebagaimana dalam Tabel 3.3 berikut : 
Tabel 1. Populasi dan Sampel Penelitian

\begin{tabular}{|c|l|c|}
\hline No. & \multicolumn{1}{|c|}{ Bagian } & $\begin{array}{c}\text { Jumlah } \\
\text { Orang }\end{array}$ \\
\hline 1 & Direktur & 1 \\
\hline 2 & Personalia & 1 \\
\hline 3 & Keuangan & 1 \\
\hline 4 & Akuntansi & 2 \\
\hline 5 & Programmer & 1 \\
\hline 6 & Controller & 1 \\
\hline 7 & Manajer & 3 \\
\hline 8 & Supervisor & 2 \\
\hline 9 & Administrasi & 6 \\
\hline 10 & Gudang & 5 \\
\hline & Jumlah Populasi & $\mathbf{2 3}$ \\
\hline
\end{tabular}

Berdasarkan data yang didapat di atas, pegawai atau karyawan terkait dengan judul di Toko Besi dan Bangunan Serba Guna di Ajibarang adalah sebanyak 23 orang, yang kemudian angka tersebut dijadikan populasi.

\section{Prosedur Pengumpulan Data}

1. Studi Kepustakaan

Melalui studi kepustakaan ini didapatkan data sekunder. Data sekunder adalah data yang diperoleh dengan cara mempelajari buku-buku, literatur, dan catatan tertulis lainnya.

2. Kuesioner

Menurut Suharsimi Arikunto (2002:128) kuesioner yaitu sejumlah pertanyaan tertulis yang digunakan untuk memperoleh informasi dari responden dalam arti laporan tentang pribadinya atau hal-hal yang ia ketahui. Kuesioner ini merupakan data primer yang diperoleh dari hasil pengisian kuesioner oleh para responden yang bersangkutan dengan masalah yang diteliti.

\section{HASIL PENELITIAN DAN PEMBAHASAN \\ Uji Normalitas}

Dari gambar uji normalitas diperoleh grafik membentuk lonceng, hal ini dapat diartikan bahwa datanya tergolong normal.

\section{Uji Validitas dan Reliabilitas}

Dari uji validitas diperoleh nilai semua pertanyaan baik untuk SIA maupun PIPB mempunyai nilai $>0,374$ sehingga semua pertanyaan dalam penelitian ini valid.

Dari uji reliabilitas diperoleh nilai korelasi untuk variabel SIA sebesar 0,749 sedangkan untuk variabel PIPB sebesar 0.701 yang lebih besar 0,374 sehingga pertanyaan yang digunakan dalam penelitian ini reliabel.

\section{Sistem Informasi Akuntansi}

Berdasarkan tabulasi jawaban responden mengenai Sistem Informasi Akuntansi Persediaan Barang di Toko Besi dan Bangunan Serba Guna di Ajibarang dapat dikatakan baik, karena nilai rata-rata keseluruhan pernyataan adalah 3.79 dan berada pada interval $3.01-4.00$ ( Baik ). 


\section{Pengendalian Internal Persediaan}

Berdasarkan tabulasi jawaban responden mengenai Pengendalian Intern Persediaan Barang di Toko Besi dan Bangunan Serba Guna di Ajibarang dapat dikatakan baik, karena nilai rata-rata keseluruhan pernyataan adalah 4.11 dan berada pada interval $4.01-5.00$ (Sangat Baik )

\section{Analisis Korelasi}

Untuk menguji ada tidaknya hubungan antara Sistem Informasi Akuntansi persediaan barang (X) dengan Pengendalian Intern persediaan barang (Y) pada Toko Besi dan Bangunan Serba Guna di Ajibarang penulis melakukan analisis korelasi (Pearsons Correlation) dengan menggunakan software SPSS 20.0 for Windows.

Tabel 2. Correlations

\begin{tabular}{|l|r|r|}
\hline & $\mathrm{X}$ & $\mathrm{Y}$ \\
\hline $\begin{array}{l}\text { Pearson } \\
\text { Correlation }\end{array}$ & 1 & $.750^{* *}$ \\
\hline Sig. (2-tailed) & & .000 \\
\hline $\mathrm{N}$ & 20 & 20 \\
\hline $\begin{array}{l}\text { Pearson } \\
\text { Correlation }\end{array}$ & $.750^{* *}$ & 1 \\
\hline Sig. (2-tailed) & .000 & \\
\hline N & 20 & 20 \\
\hline **. Correlation is significant at the 0.01
\end{tabular}

level (2-tailed).

Berdasarkan hasil pengolahan data pada tabel 2 didapat hasil koefisien korelasi sebesar 0,750. Apabila korelasi tersebut diinterpretasikan dalam tabel, maka Variabel Sistem Informasi
Akuntansi persediaan barang $(\mathrm{X})$ dengan variabel Pengendalian Intern persediaan barang (Y) memiliki hubungan yang positif, yakni sebesar 0,750. Angka ini menunjukan bahwa hubungan Sistem Informasi Akuntansi persediaan barang dengan Pengendalian Intern persediaan barang bisa dikatakan sangat tinggi atau sangat kuat.

Nilai korelasi yang positif menunjukan bahwa semakin tinggi Sistem Informasi Akuntansi persediaan barang maka diprediksi Pengendalian Intern persediaan barang pada Toko Besi dan Bangunan Serba Guna di Ajibarang cenderung meningkat.

\section{Analisis Regresi}

Tabel 3. Coefficients ${ }^{\mathrm{a}}$

\begin{tabular}{|c|c|c|c|c|c|}
\hline \multirow[b]{2}{*}{ spModel } & \multicolumn{2}{|c|}{$\begin{array}{l}\text { Unstandardize } \\
\text { d Coefficients }\end{array}$} & $\begin{array}{c}\text { Standar } \\
\text { dized } \\
\text { Coeffici } \\
\text { ents }\end{array}$ & & \\
\hline & B & $\begin{array}{l}\text { Std. } \\
\text { Error }\end{array}$ & Beta & $\mathrm{t}$ & Sig. \\
\hline $\begin{array}{ll}1 & \text { (Consta } \\
& \mathrm{nt})\end{array}$ & .327 & .863 & & .379 & .709 \\
\hline$X$ & .895 & .186 & .750 & $\begin{array}{r}4.81 \\
4\end{array}$ & .000 \\
\hline
\end{tabular}

a. Dependent Variable: Y

Berdasarkan tabel 3 persamaan linear untuk $\mathrm{x}$ dan y adalah :

$$
\mathrm{Y}=0,327+0,895 \mathrm{X}
$$

Artinya jika variabel $\mathrm{X}$ bertambah 1 satuan, maka variabel $\mathrm{Y}$ akan bertambah 


\section{Performance - Vol.22 No.2 September 2016}

0,895 satuan variabel Sistem Informasi Akuntansi persediaan barang (X) memiliki nilai koefisien regresi (B) sebesar 0,895. Hal ini menunjukkan bahwa jika tidak ada penambahan Sistem Informasi Akuntansi persediaan barang maka Pengendalian Intern persediaan barang 0,327. Dan jika ada penambahan Sistem Informasi Akuntansi persediaan barang maka Pengendalian Intern persediaan barang sebesar 0,895 .

\section{Koefisien Determinasi}

Untuk mengetahui besarnya pengaruh variabel X ( Sistem Informasi Akuntansi persediaan barang ) dalam variabel Y ( Pengendalian Intern persediaan barang ) akan dicari dengan menghitung Koefisien Determinasi ( Kd ) dengan rumus sebagai berikut :

$$
\begin{aligned}
\mathrm{Kd} & =(\mathrm{RS})^{2} \times 100 \% \\
& =(0,750)^{2} \times 100 \% \\
& =56,30 \%
\end{aligned}
$$

Untuk mempermudah perhitungan tersebut dilakukan menggunakan SPSS 17.0 for windows. Berikut hasil perhitungan koefisien determinasi $\mathrm{X}$ dan Y.

Tabel 4. Model Summary

\begin{tabular}{|c|c|r|c|c|}
\hline Model & $\mathrm{R}$ & $\begin{array}{c}\mathrm{R} \\
\text { Square }\end{array}$ & $\begin{array}{c}\text { Adjusted } \\
\text { R Square }\end{array}$ & $\begin{array}{c}\text { Std. } \\
\text { Error of } \\
\text { Estimate }\end{array}$ \\
\hline $\mathbf{1}$ & $\mathbf{. 7 5 0}^{\mathrm{a}}$ & $\mathbf{. 5 6 3}$ & $\mathbf{. 5 3 9}$ & $\mathbf{. 4 1 7 3 5}$ \\
\hline \multicolumn{4}{|c|}{ a . Predictors : (Constant), SIA pers. barang } \\
\hline
\end{tabular}

Dari hasil perhitungan dengan menggunakan rumus koefisien determinasi dan penggunaan program SPSS 17.00 for windows diperoleh bahwa nilai $(\mathrm{RS})^{2}$ adalah 0,563 sama artinya Sistem Informasi Akuntansi persediaan barang berpengaruh terhadap Pengendalian Intern persediaan barang sebesar 56,30\% sedangkan 43,70\% dipengaruhi oleh faktor lain. Atau dapat diartikan pula bahwa Sistem Informasi Akuntansi persediaan barang berperan dalam Pengendalian Intern persediaan barang pada Toko Besi dan Bangunan Serba Guna di Ajibarang adalah sebesar $56,30 \%$.

\section{KESIMPULAN DAN SARAN \\ Kesimpulan}

Berdasarkan hasil penelitian dan pembahasan mengenai Sistem Informasi Akuntansi Persediaan Barang terhadap Pengendalian Internal Persediaan Barang pada Toko Besi dan Bangunan Serba Guna di Ajibarang, maka penulis menarik kesimpulan sebagai berikut:

1. Pelaksanaan Sistem Informasi Akuntansi Persediaan Barang yang meliputi Perangkat Keras (hardware), Perangkat Lunak (software), Manusia (brainware), prosedur dan database pada Toko Besi dan Bangunan Serba Guna di Ajibarang dapat dikatakan baik dengan nilai 3,79 ;

2. Pengendalian Intern Persediaan Barang yang meliputi lingkungan pengendalian, penetapan resiko, 
aktifitas pengendalian, informasi dan komunikasi dan pemantauan dapat dikatakan sangat baik dengan nilai 4,11; dan

3. Sistem Informasi Akuntansi Persediaan Barang dapat dikatakan berpengaruh terhadap Pengendalian Intern Persediaan Barang pada Toko Besi dan Bangunan Serba Guna di Ajibarang sebesar 56,30 \%.

\section{Saran}

Berdasarkan kesimpulan diatas, penulis mencoba untuk memberikan beberapa saran perbaikan yang dapat digunakan sebagai dasar pertimbangan atau masukan pada Toko Besi dan Bangunan Serba Guna di Ajibarang berkaitan dengan penerapan Sistem Informasi Akuntansi Persediaan Barang dengan Pengendalian Intern Persediaan Barang :

1. Sistem Informasi Akuntansi Persediaan Barang

- Kelengkapan dan kecepatan hardwaresebaiknya lebih ditingkatkan lagi dan diperbaharui karena hal ini akan menunjang kegiatan operasional perusahaan lebih efektif dan efisien.

- Prosedur yang sudah ada sebaiknya dijalankan sesuai dengan ketentuan yang berlaku, apabila ada perubahan prosedur sebaiknya dipikirkan dengan matang dan disosialisasikan terlebih dahulu.
2. Pengendalian Intern Persediaan Barang

- Mengenai penetapan resiko, perusahaan sebaiknya lebih mengantisipasi jika terdapat perubahan dalam perusahaan dan lingkungan pengendalian. Apabila ada karyawan baru sebaiknya lebih selektif sehingga karyawan baru tersebut dapat mengikuti sistem yang sudah ada dan dapat menjalankan tugas dan tanggung jawabnya dengan baik.

- Dalam struktur organisasi harus tergambar garis wewenang dan tanggung jawab di Toko Besi dan Bangunan Serba Guna di Ajibarang sehingga semua pegawai dapat mengerti wewenang dan tanggung jawabnya masing-masing.

- Perusahaan sebaiknya lebih meningkatkan pengamanan asset dan dokumen catatan agar tidak terjadi kerusakan dan kehilangan terkait persediaan barang.

\section{DAFTAR PUSTAKA}

Arens, Alvin A, Elder dan Beasley, 2015. Auditing, Prentice Hall, Inc New Jersey.

Azhar Susanto dan La Midjan, 2013.Sistem Informasi Akuntansi I, Lingga Jaya, Jakarta.

Azhar Susanto, 2013. Sistem Informasi Akuntansi, Lingga Jaya, Jakarta. 


\section{Performance - Vol.22 No.2 September 2016}

Ikatan Akuntansi Indonesia, 2012. Mulyadi, 2013. Sistem Informasi Standar Akuntansi Keuangan, Akuntansi, Salemba Empat, Jakarta. Salemba, Jakarta. Sugiyono, 2013. Model Penelitian Bisnis, CV. Alfabeta, Bandung.

Mudjarad Kuncoro. 2014. Metode Riset Sugiyono, 2013. Statistika Untuk Untuk Bisnis dan Ekonomi. Jakarta : Erlangga.

Penelitian, CV. Alfabeta, Bandung.

Mohammad Nazir, 2014. Metode Penelitian, Ghalia, Jakarta. 
http://jp.feb.unsoed.ac.id 